\title{
Demographic and health time-series analysis of small areas in GB: the development of area measures and population estimates
}

\begin{abstract}
In health and other applied studies, there is a need for populations as denominators and measures of area type as covariates by time point and small area geographies. The work referred to here demonstrates how resources have been developed and made available to other researchers which subsequently has been reported in numerous journal articles. Some of the work has been area based and some about outcomes for individuals. Recently, the estimates and area type measures have been updated and extended so as to underpin current research. This work is ongoing and will be reported in time but the resources used as denominators and area types are now available to the wider research community. This short paper gives an overview of the relevant research and points others to the source of freely downloadable datasets.
\end{abstract}

Volume 6 Issue 4 - 2017

\author{
Paul Norman \\ School of Geography, University of Leeds, UK
}

Correspondence: Paul Norman, School of Geography, University of Leeds, UK, Tel +44 (0) II 334 38I99, Email p.d.norman@leeds.ac.uk

Received: September 22, 2017 | Published: November 06, 2017

\section{To date}

The need for population estimates and measures of area type was demonstrated by Norman. ${ }^{1}$ Essentially, at appropriate time points and by small geographical areas, populations by age and sex are needed as denominators in rates and area type measures, particularly deprivation measures, are needed as covariates in models. Various publications report on the production of a set of sub national small area population related resources for GB and the UK through the development of methods: for geographical harmonisation when small area boundaries change, 2,3 of populations by age and sex in terms of the estimation of the past ${ }^{4-7}$ and projection of the future [8-11]; of the calculation of changing area deprivation; ${ }^{12}$ and of the analysis of demographic change. ${ }^{13-15}$ The resources relate to the period 1981 to 2001 with very full detail (relevant to the purposes) though with less detail from 1971 to 1981 and after 2001. Various datasets have been deposited at the UK Data Archive (study numbers 5850, $6045 \&$ 6777). The same methods have been used to analyse changing deprivation for small areas in Australia. ${ }^{16}$ In applied work, the resources have mainly been used for health related research of; infant mortality, ${ }^{17}$ all cause mortality, ${ }^{18,19}$ cause specific mortality: ${ }^{20}$ limiting long-term illness and incapacity benefit, ${ }^{21-23}$ of children with life limiting conditions ${ }^{24,25}$ and in small animal veterinary practice. ${ }^{26}$ Further topics include small area analyses of local democracy, ${ }^{27}$ environmental equity, ${ }^{28}$ traffic accidents $^{29}$ and fire risk. ${ }^{30}$

The examples above are area based; about whether aspects for small populations vary over space and time. Parallel to this, research has sought to determine whether for individuals, there are different experiences for people who live in different kinds of places over time. As above, the focus is on health, particularly for persons: who move between levels of deprivation ${ }^{31,32}$ at different ages ${ }^{33}$ or between urban and rural areas ${ }^{34}$ in different countries from where they were born; ${ }^{35,36}$ who do not move residence; ${ }^{37}$ or who are socially mobile; $; 8$ and where linkages to residential areas need estimation when specific locations are unclear or names of places have changed. ${ }^{39}$ Analogous situations for cardiovascular disease have been researched in New Zealand. ${ }^{40,41}$ As knowledge of the availability of the demographic resources became more widely known, various researchers specified custom data requests for ongoing research. These resulting studies included research into general cancer; ${ }^{42-44}$ specific cancers, ${ }^{45-51}$ coronary heart disease, ${ }^{52-54}$ coronary intervention treatment, ${ }^{55,56}$ diabetes, ${ }^{57,58}$ asthma, ${ }^{59,60}$ hearing and visual impairment, ${ }^{61-63}$ muscular dystrophy ${ }^{64}$ and neuromuscular disease. ${ }^{65}$

\section{To update}

More recent data are now available (both census and demographic births and deaths events) but with the inevitable boundary and data definitional changes which were resolved in the previous work. There was therefore a need to update, to redefine and to ensure the resources were fit for purpose for long run time-series analysis from 1971 to 2011 and by contemporary geographies (2011 definitions). The latter ensures that interpretations are relevant to current applications. Demand was building from various directions for the resources to be revised and made available. Initially, a partial solution was needed for the Government's Foresight future cities initiative (work with Rees \& Durham) and a proposal for future work was made to Joseph Rowntree (with Birkin, Malleson \& Clarke). Previous collaborators at Leeds (Mitchell; Feltbower \& Parslow), York (Fraser) and at Newcastle (McNally \& colleagues) needed updated information and fuller resources for ongoing research. There are also new opportunities with researchers at Leeds (Connor), UCL (Jivraj \& Murray), Manchester (Dawes and Becares), Nottingham (Edmondson-Jones) and Kings (Polling; Woodhead) all of whom want to link individual data to area characteristics for studies: of health and well-being through the life course; of visual and hearing impairment; of self harm and mental health using: longitudinal and cohort studies, hospital episode (in \& out patients, A\&E), the UK Biobank, etc. Public Health England (via Edwards in Birmingham) are keen to have annual population estimates for use as denominators in cancer rates.

\section{Outputs}

The aim was to produce for small area sub national areas in England, Wales and Scotland various datasets which comprise:

i. 1971-2001 annual time-series of populations by five year age-groups and sex; 
ii. Population density for the census years, 1971, 1981, 1991, 2001 and 2011;

iii. Deprivation scores and quintiles for the census years, 1971, 1981, 1991, 2001 and 2011;

iv. Socio demographic variables (the inputs to deprivation measures).

To create the above requires data to be converted from their original geographies of dissemination (different at least once per decade) to the small area geographies for which the 2011 Census data were released: i.e. Super Output Areas in England and Wales and Data zones in Scotland. A lack of data over this time-frame precludes widening out the (vector) geographical coverage to include Northern Ireland but equivalent data will be made available for 1991, 2001 and 2011. See Lloyd ${ }^{66}$ for a solution using population surfaces across the UK. The development of the resources and initial analyses are reported in Norman ${ }^{67}$ and Norman et al. ${ }^{68}$ and have been used in studies of accessibility to sports facilities ${ }^{69}$ and of inequities in improvements in air quality. ${ }^{70}$ The time-series of GB deprivation and density measures have been attached to the 1958 and 1970 British Birth Cohorts for a study at $\mathrm{UCL}^{71}$ and an equivalent dataset for England and Wales for attachment to the ONS Longitudinal Study (via Dennett at Celsius).

\section{Conclusion}

Populations by age and sex and measures of area type by time point and small area geographies have been used by the research community in the UK. Some of the work has been area based and some about outcomes for individuals and without the resources provided, the research could not have gone ahead so readily. The estimates and area type measures have recently been updated and extended o underpin current research. This work is ongoing and will be reported in time but the resources used as denominators and area types are now available freely to the wider research community. This short paper gives an overview of the relevant research and points others to the source of readily downloadable datasets. ${ }^{72}$

\section{Acknowledgement}

None.

\section{Conflict of interest}

Author declares that there is no conflict of interest.

\section{References}

1. Norman P. Estimating small area populations for use in medical studies: Accounting for population migration. UK: University of Leeds; 2002.

2. Norman P, Rees P, Boyle P. Achieving data compatibility over space and time: creating consistent geographical zones. Population, Space and Place. 2003;9(5):365-386.

3. Norman P. Sociodemographic spatial change in the UK: data and computational issues and solutions. GIS Development. 2006;10(12):30-34.

4. Rees P, Norman P, Brown D. A framework for progressively improving small area population estimates. Series A: Statistics in Society. 2004;167(1):5-36.

5. Rees P, Parsons J, Norman P. Making an estimate of the number of people \& households for Output Areas in the 2001 Census. Popul Trends. 2005;122:27-34.

6. Norman P, Simpson L, Sabater A. 'Estimating with Confidence' and hindsight: new UK small area population estimates for 1991. Popula- tion, Space and Place. 2008;14(5):449-472.

7. Lomax N, Norman P. Estimating population attribute values in a table: 'get me started in' Iterative Proportional Fitting (IPF). The Professional Geographer. 2006;68(3):451-461.

8. Norman P, Rees P, Wohland P, et al. Ethnic group populations: the components for projection, demographic rates and trends. Ethnicity and Integration. Series:Understanding Population Trends and ProcessSes. 2010;3:289-315.

9. Rees P, Wohland P, Norman P. The demographic drivers of future ethnic group populations for UK local areas 2001-2051. Geographical Journal. 2010;179(1):44-60.

10. Rees P, Wohland P, Norman P, et al. A local analysis of ethnic group population trends and projections for the UK. Journal of Population Research. 2011;28(2-3):149-183.

11. Rees P, Wohland P, Norman P, et al. Ethnic population projections for the UK, 2001-2051. Journal of Population Research. 2012;29(1):45-89.

12. Norman P. Identifying change over time in small area socio-economic deprivation. Applied Spatial Analysis and Policy. 2010;3(2-3):107-138.

13. Tromans N, Natamba E, Jefferies J, et al. Have national trends in fertility between 1986 and 2006 occurred evenly across England and Wales? Popul Trends. 2008;133:7-19.

14. Norman P. Demographic and deprivation change in the UK, 1991-2001. In Understanding Population Trends and Processes book series (UPTA, Volume 2): Spatial and Social Disparities. Netherlands: Springer; 2010. p. $17-35$.

15. Norman P. Relationships between UK sub national trends in infant mortality and fertility. In Population Dynamics and Projection Methods (UPTAP Volume 4), Netherlands: Springer; 2011. p. 99-114.

16. Norman P, Charles-Edwards E, Wilson T. Relationships between population change, deprivation change and health change at small area level:Australia 2001-2011. Demography for Planning and Policy: Australian Case Studies, Switzerland: Springer; 2016. p. 197-214.

17. Norman P, Gregory I, Dorling D, et al. Geographical trends in infant mortality: England and Wales, 1970-2006. Health Statistics Quarterly. 2008;40:18-29.

18. Rees P, Brown D, Norman P, et al. Are socioeconomic inequalities in mortality decreasing or increasing within some British regions? An observational study, 1990-98. Journal of Public Health Medicine. 2003;25(3):208-214.

19. Norman P, Boyle P, Exeter D, et al. Rising premature mortality in the UK's persistently deprived areas: Only a Scottish phenomenon? Soc Sci Med. 2011;73(11):1575-1584.

20. Exeter DJ, Boyle PJ, Norman P. Deprivation (im) mobility and causespecific premature mortality in Scotland. Soc Sci Med. 2011;72(3):389397.

21. Bambra C, Norman P. What is the association between sickness absence, morbidity and mortality? Health Place. 2006;12:728-733.

22. Norman P, Bambra C. Unemployment or incapacity? The utility of medically certified sickness absence data as an updatable indicator of population health. Population, Space \& Place. 2007;13(5):333-352.

23. Ajebon M, Norman P. Beyond the census: a spatial analysis of health and deprivation in England. Geo Journal. 2016;81(3):395-410.

24. Fraser LK, Miller M, Hain R, et al. Rising national prevalence of Life Limiting Conditions in Children in England. Pediatrics. 2012;129(4):e923e929. 
25. Norman P, Fraser L. Prevalence of life-limiting and life-threatening illness in children and young people in England: time trends by area type. Health Place. 2014;26:171-179.

26. Cave TA, Norman P, Mellor D. Cytotoxic drug use in treatment of dogs and cats with cancer by UK veterinary practices (2003 to 2004). J Small Anim Pract. 2007;48(7):371-377.

27. Norman P, Purdam K, Tajar A, et al. Representation and local democracy: geographical variations in elector to councillor ratios. Political Geography. 2007;26(1):57-77.

28. Mitchell G, Norman P. Longitudinal environmental justice analysis: Coevolution of environmental quality and deprivation in England, 1960 2007. Geoforum. 2012;43(1):44-57.

29. Lyons RA, Ward H, Christie N, et al. Road traffic injury and disadvantage: people and areas. Behavioural Research in Road Safety 2007, UK; 2009. p. 77-93.

30. Corcoran J, Higgs G, Brunsdon C, et al. The use of spatial analytica techniques to explore patterns of fire incidence: a South Wales case study. Computers, Environment and Urban Systems. 2007;31(6):623-647.

31. Boyle P, Norman P, Rees P. Does migration exaggerate the relationship between deprivation and limiting long-term illness? A Scottish analysis. Soc Sci Med. 2002;55(1):21-31.

32. Norman P, Boyle P, Rees P. Selective migration, health and deprivation: a longitudinal analysis. Soc Sci Med. 2005;60(12):2755-2771.

33. Norman P, Boyle P. Are health inequalities between differently deprived areas evident at different ages? A longitudinal study of census records in England \& Wales, 1991-2001. Health Place. 2014;26:88-93.

34. Riva M, Curtis S, Norman P. Residential mobility within England and urban-rural inequalities in mortality. Soc Sci Med. 2011;73(12):16981706.

35. Norman P. Country of birth and country of residence influences on selfreported health: a British analysis using individual-level data. White Rose Research Online, UK; 2008. p. 1-18.

36. Popham F, Boyle P, Norman P. The Scottish excess in mortality compared to the English and Welsh: Is it a country of residence or country of birth excess? Health Place. 2010;16(4):759-762.

37. Boyle P, Norman P, Rees P. Changing places: do changes in the relative deprivation of areas influence limiting long-term illness and mortality among non-migrant people living in non-deprived households? Soc Sci Med. 2004;58(12):2459-2471.

38. Boyle P, Norman P, Popham F. Social mobility: evidence that it can widen health inequalities. Soc Sci Med. 2009;68(10):1835-1842.

39. Norman P, Riva M. Population health across space and time:the geographical harmonisation of the ONS Longitudinal Study for England and Wales. Population, Space \& Place. 2012;18(5):483-502.

40. Darlington-Pollock F, Shackleton N, Norman P, et al. Differences in the risk of cardiovascular disease for movers and stayers in New Zealand:A survival analysis. Int J Public Health. 2017. p. 1-7.

41. Darlington-Pollock F, Norman P, Lee A, et al. To move or not to move? Exploring the relationship between residential mobility, risk of CVD and ethnicity in New Zealand. Soc Sci Med. 2016;165:128-140.

42. Van Laar M, Mc Kinney PA, Parslow RC, et al. Cancer incidence among the south Asian and non-south Asian population under 30 years of age in Yorkshire, UK. Br J Cancer. 2010;103(9):1448-1452.

43. Van Laar M, Mc Kinney PA, Parslow RC, et al. Cancer incidence among the south Asian and non-south Asian population under 30 years of age in Yorkshire, UK. Br J Cancer. 2013;108(9):1448-1452.
44. Van Laar M, Mc Kinney PA, Stark DP, et al. Survival trends of cancer among the south Asian and non-south Asian population under 30 years of age in Yorkshire, UK. Cancer Epidemiol. 2012;36(1):e13-e18.

45. Basta NO, James PW, Gomez-Pozo B, et al. Survival from teenage and young adult cancer in northern England, 1968-2008. Pediatr Blood Cancer. 2014;61(5):901-906.

46. Blakey K, Feltbower RG, Parslow RC, et al. Is fluoride a risk factor for bone cancer? Small area analysis of osteosarcoma and Ewing sarcoma diagnosed among 0-49 year olds in Great Britain, 1980-2005. Int J Epidemiol. 2014;43(1):224-234.

47. McNally RJ, Basta NO, Errington S, et al. Socio-economic patterning in the incidence and survival of boys and young men diagnosed with testicular cancer in northern England. Urologic Oncology: Seminars and Original Investigations. 2015;33(12):506.E9-505.E14.

48. Mc Nally RJQ, Blakey K, Parslow RC, et al. Small area analyses of bone cancer diagnosed in Great Britain provide clues to aetiology. BMC Cancer. 2012;12:270.

49. Mc Nally RJQ, James PW, Blakey K, et al. Can changes in population mixing and socio-economic deprivation in Cumbria, England explain changes in cancer incidence around Sellafield? Spatial and Spatio-temporal Epidemiology. 2017;21:25-36.

50. Mc Nally RJQ, James PW, Ducker S, et al. No rise in incidence but geographical heterogeneity in the occurrence of Primary Biliary Cirrhosis in northeast England. Am J Epidemiol. 2014;179(4):492-498.

51. Smith L, Norman P, Kapetanstrataki M, et al. Comparison of ethnic group classification using naming analysis and routinely collected data:application to cancer incidence trends in children and young people. BMJ Open. 2017;7(9):e016332.

52. Bajekal M, Scholes S, O'Flaherty M, et al. Implications of using a fixed IMD quintile allocation for small areas in England from 1981 to 2007. PLoS One. 2013;8(3):e59608.

53. Bajekal M, Scholes S, O'Flaherty M, et al. Unequal trends in coronary heart disease mortality by socioeconomic circumstances, England 1982-2006:analytical study. PLoS One. 2013;8(3):e59608.

54. Scholes S, Bajekal M, Norman P, et al. Quantifying policy options for reducing future coronary heart disease mortality in england: a modelling study. PLoS One. 2013;8(7):e69935.

55. Dondo TB, Hall M, Timmis AD, et al. Geographic variation in the treatment of non ST-segment myocardial infarction in the English National Health Service:a cohort study. BMJ Open. 2016;6(7):e011600.

56. Hall M, Laut K, Dondo T, et al. Patient and hospital determinants of primary percutaneous coronary intervention in England, 2003-13. Heart. 2016;102:313-319.

57. Harron K, McKinney PA, Feltbower RG, et al. Incidence rate trends in childhood Type 1 diabetes in Yorkshire, UK 1978-2007:effects of deprivation and age at diagnosis in the south Asian and non-south Asian populations. Diabet Med. 2011;28(12):1508-1513.

58. Harron K, McKinney PA, Feltbower RG, et al. Ethnic differences in incidence rates of childhood Type 1 diabetes in Yorkshire 1978-2007. Diabetologia. 2010;53:S143-S143.

59. Hoskins G, Williams B, Jackson C, et al. Assessing Asthma Control in UK Primary Care:Use of routinely collected prospective observational consultation data to determine appropriateness of a variety of control assessment models. BMC Fam Pract. 2011;12:105.

60. Hoskins G, Williams B, Jackson C, et al. Patient, practice and organizational influences on asthma control. Observational data from a national study on primary care in the United Kingdom. International Journal of Nursing Studies. 2012;49(5):596-609. 
61. Dawes P, Dickinson C, Emsley R, et al. Vision impairment and dual sensory problems in middle age. Ophthalmic Physiol Opt. 2014;34(4):479 488.

62. Dawes P, Dickinson C, Emsley R, et al. Understanding visual impairment in UK Biobank- Authors' Reply. Ophthalmic Physiol Opt. 2015;35(1):107-108.

63. Dawes P, Fortnum H, Moore DR, et al. Hearing in middle age: a population snapshot of 40 to 69year olds in the United Kingdom. Ear Hear. 2014;35(3):e44-51

64. Pierotti L, Mohammed MA, Wildman M, et al. Using funnel plots to make meaningful centre comparisons. Journal of Cystic Fibrosis. 2015;14(Suppl 1):S33.

65. Woodcock IR, Fraser L, Norman P, et al. The prevalence of neuromuscular disease in the pediatric population in Yorkshire, UK:variation by ethnicity and deprivation status. Dev Med Child Neurol. 2016;58(8):877883.

66. Lloyd CD. Creating Population Surfaces for the Analysis of Small Area Change. The Frontiers of Applied Demography. Switzerland: Springer International Publishing; 2017. p. 431-448.
67. Norman P. The Changing Geography of Deprivation in Britain:1971 to 2011 and Beyond. Population change in the United Kingdom. UK: Rowman \& Littlefield; 2016. p. 1-28.

68. Norman P, Darlington-Pollock F. The changing geography of deprivation in great britain: exploiting small area census data, 1971 to 2011. The Routledge Handbook of Census Resources, Methods and Applications: Unlocking the UK 2011 Census. International Population Studies, Routledge, UK; 1971. p. 404-420.

69. Higgs G, Langford M, Norman P. Accessibility to sports facilities in Wales: a GIS-based analysis of socio-economic variations in provision. Geoforum. 2015;62:105-120.

70. Mitchell G, Norman P, Mullin K. Who benefits from environmental policy? An environmental justice analysis of air quality change in Britain, 2001-2011. Environ Res Lett. 2015;10(10).

71. Jivraj S, Nicholas O, Murray E, et al. Associations between childhood neighbourhood deprivation and later life health. LSE, UK; 2017.

72. Norman P. Area characteristics: Great Britain 1971 to 2011. Mendeley; 2017. 